\title{
Characterize the Demand and Energy \\ Characteristics of Residential Electric Vehicle Supply Equipment
}

Idaho National Laboratory

June 2015

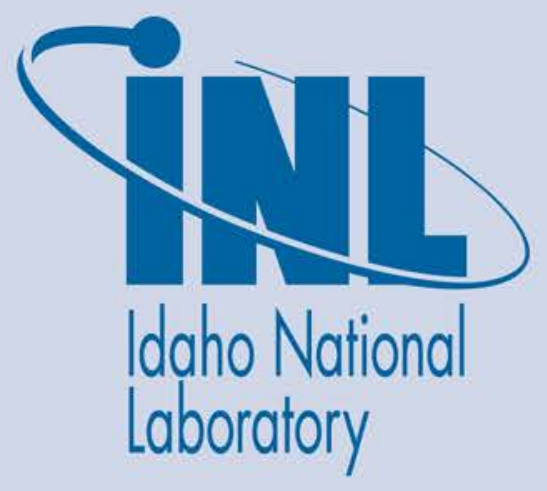

The INL is a U.S. Department of Energy National Laboratory operated by Battelle Energy Alliance 


\title{
Characterize the Demand and Energy Characteristics of Residential Electric Vehicle Supply Equipment
}

\author{
Idaho National Laboratory
}

June 2015

\section{Idaho National Laboratory \\ Idaho Falls, Idaho 83415}

http://www.inl.gov 


\section{Characterize the Demand and Energy Characteristics of Residential Electric Vehicle Supply Equipment}

June 2015

\section{Key Conclusions}

- Actual charge data from The EV Project show that most plug-in electric vehicles (PEVs) participating in the EV Project charged up to $3.76 \mathrm{~kW}$, with some of the 2013 model vehicles reaching 6.64 kW.

- Electric utilities, without time-of-use (TOU) rates, can expect a median peak demand of 0.8 times the number of PEVs in the service territory. In The EV Project, this peak occurred at approximately 10 p.m.

- Electric utilities, offering TOU rates, can expect a median peak demand of $1.7 \mathrm{~kW}$ times the number of PEVs in the service territory. In The EV Project, this peak occurred within approximately 1 hour of the start of the greatest incentive period.

- Each day, approximately 88\% of PEV owners in The EV Project charged their PEV.

- The average PEV charge lasted approximately 2 hours and 15 minutes and consumed $8.4 \mathrm{kWh}$ of energy.

\section{Introduction}

The EV Project enrolled over 8,000 residential participants. These participants purchased or leased a Nissan Leaf or Chevrolet Volt. The EV Project provided and installed Blink electric vehicle supply equipment (EVSE) that was used to recharge their PEV, in exchange for their agreement to allow project analysts to evaluate data collected from charging their PEV at their residence and away from home. The power required to recharge a PEV can be a significant contributor to the electrical load a residence places on the electric grid. What insight can The EV Project data provide in characterizing this contribution in terms of power demand and energy consumption to assist electric utilities in PEV adoption planning?

\section{Why is This Topic Important?}

A question frequently asked relating to the adoption of PEVs is "What is the impact of PEV charging on the electrical grid?" This question can be directed at the big picture of total utility system load or on the impact to the local electrical distribution system and, in particular, the local residential electrical transformer. The effects of clustering on the local transformer by several neighbors simultaneously charging PEVs was addressed in "What Residential Clustering Effects have been Experienced in the San Diego Region?"1

This paper focuses on the impact to the total system load and identification of a typical residential charge profile or load duration curve.

\section{Data Analyzed}

The EV Project published reports on a quarterly basis on the specific aggregated charge data. Electric utilities within the boundaries of The EV Project requested specific information related to the demand and energy requirements for residential charging of PEVs. These reports are available at avt.inl.gov/evproject.shtml. The utilities also received reports for their service territories. Information from the quarterly reports was analyzed for this report.

Data points investigated herein are regional median power demand, number of participants, energy consumed, hours connected, hours drawing power, average number of charging events started per EVSE per day, and average energy consumed per charging event. These data points are available for both weekday and weekend time periods. The weekday data points are used herein.

The charge rate and demand for energy to recharge the battery are determined by the PEV's onboard battery management system. The Blink EVSE provided to EV Project participants were capable of delivering up to $7.2 \mathrm{~kW}$ power to a connected PEV. Charge data from The EV Project show that most PEVs participating in the EV Project charged at $3.76 \mathrm{~kW}$ or les; a few 2013 model year vehicle's charged up to $6.64 \mathrm{~kW}$. This information is useful in understanding the potential individual household demand effects. However, because PEV owners do not charge their vehicles every night nor at the same time, analysis of their charging patterns is necessary to determine their impact on the electric grid.

\section{Demand Effects}

Figure 1 shows the aggregated charging demand for all residential EVSE in The EV Project for the first quarter of 2013. Data for charging power and energy were collected from Blink EVSE installed by The EV Project and from PEVs participating in The EV Project.

Charging demand is defined as the total amount of power being drawn from the electric grid by a group of EVSE in a geographical area. In these figures, the demand for each day of the quarter is overlaid on the time of day; therefore, the upper blue line indicates the maximum demand over the quarter, the gray line shows the minimum demand, and the black line shows the median demand over the quarter. 
The inner quartiles are shown as gray shaded areas. The data for weekdays and weekends are graphed separately.

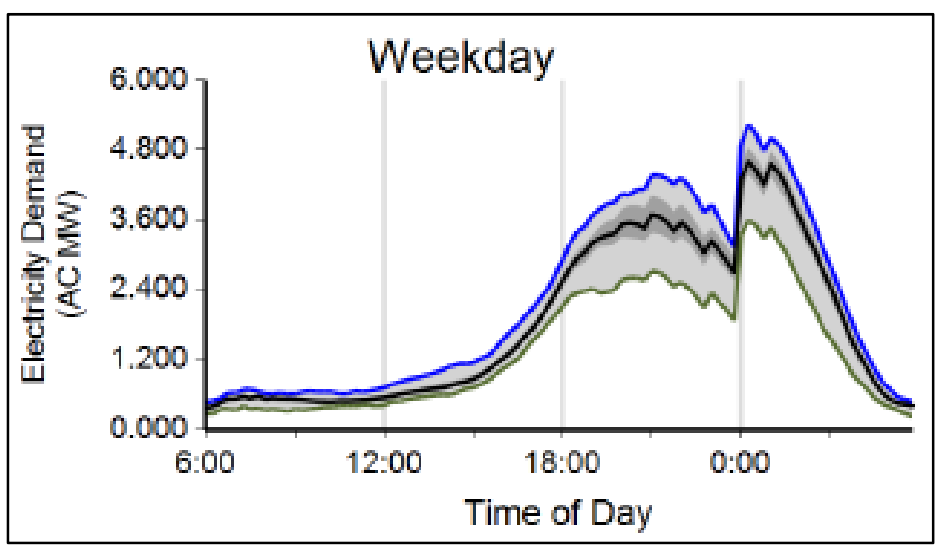

Figure 1. Aggregated residential charging demand for all regions of The EV Project during the first quarter of 2013.

Further investigation reveals that two different curves are involved in this aggregated figure. These two curves are differentiated by whether or not the electric utility offers TOU rates.

\section{Time-of-Use Rates}

Electricity generating costs to the utility can be reduced if the peak demand is lowered by shifting some demand to times of the day when the demand for electricity is low. Many electric utilities do this through financial incentives, including in TOU rates. For example, the Pacific Gas and Electric (PG\&E) utility offers TOU plans that significantly reduce energy rates during off-peak times below those rates charged during on-peak times. This topic was the focus of the report titled, How Do Plug-In Electric Vehicle Owners Respond to Time-of-Use Rates While Charging EV Project Vehicles? ${ }^{4}$ These TOU rates have a significant effect on the charging demand profile (Figures 2 and 3 , which were taken from that report).

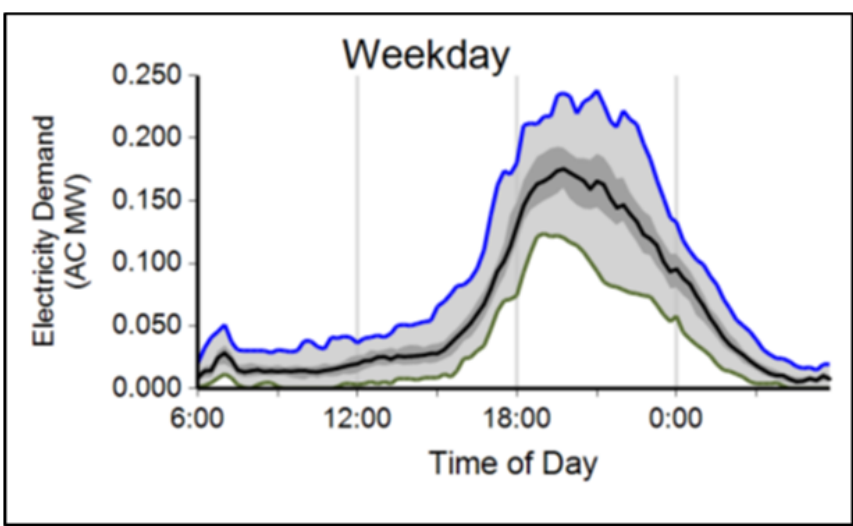

Figure 1. Weekday residential charging demand in Nashville Electric Service territory for the first quarter of 2013.

As seen in Figure 3, the incentives influence the PEV owner to shift charging to occur after midnight when the power demand on the grid is low. Thus, the investigation of demand effects must consider whether the electric utility offers TOU rates. Additionally, charging usage also varies by region, which is shown in The EV Project quarterly reports. Therefore, to characterize usage, three utilities in different regions are investigated for both TOU and non-TOU rate structures.

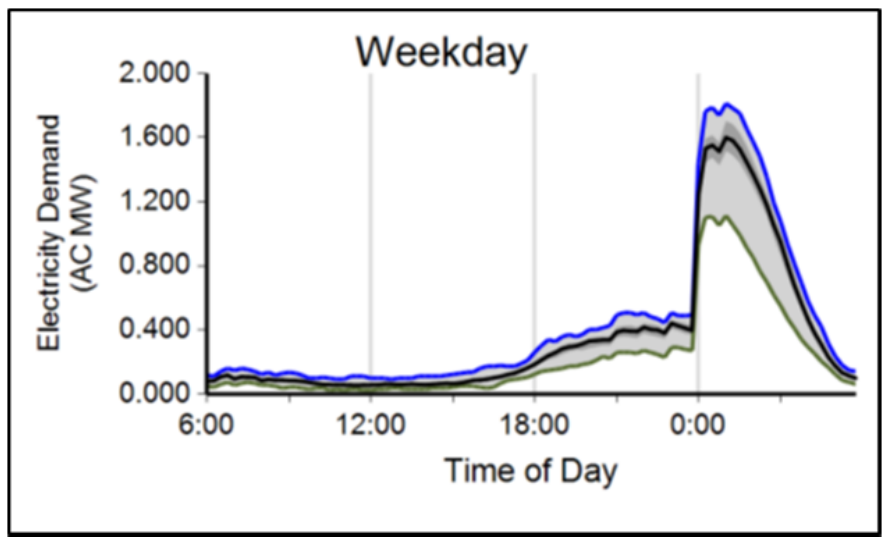

Figure 2. Weekday residential charging demand in a PG\&E territory during the first quarter of 2013.

Nashville Electric Service, Arizona Public Service, and Portland General Electric are selected as representative of utilities that do not offer TOU rates. PG\&E, San Diego Gas and Electric, and Georgia Power are selected as representative of utilities that do have TOU rates.

\section{Non-Time-of-Use Utility Demand Analysis}

The first utility reports occurred in the second quarter of 2011. The latest published electric utility quarterly report occurred in the second quarter of 2013. The first report did not differentiate between the maximum, minimum, median, and inner quartile values. This became a standard reporting practice within The EV Project during the second quarter of 2012. Figure 4 shows the growth in the median demand values over the length of the project in the three non-TOU utility service territories.

The total demand and number of participants for these three regions are shown in Figure 5.

Figure 5 shows that the median power demand is closely related to the number of participants in the project. However, participants did not charge their PEV every day. The average number of charges initiated per day per EVSE in these regions ranged from 0.56 to 0.98 with an overall average of 0.80 . This means that on average $80 \%$ of the EVSE were used to charge each day to establish the demand identified in Figure 5. (This is explored in greater detail in the following sections.) 
The average time of day for these three utilities where the maximum demand occurs is shown in Figure 6 . The demand curve for each utility has a similar appearance to that of Nashville Electric Service shown in Figure 2.

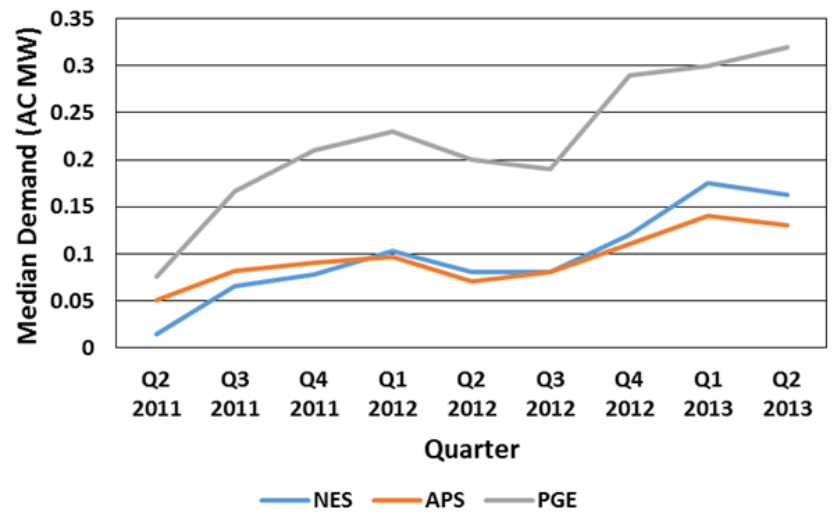

Figure 4. Non-TOU territory demand.

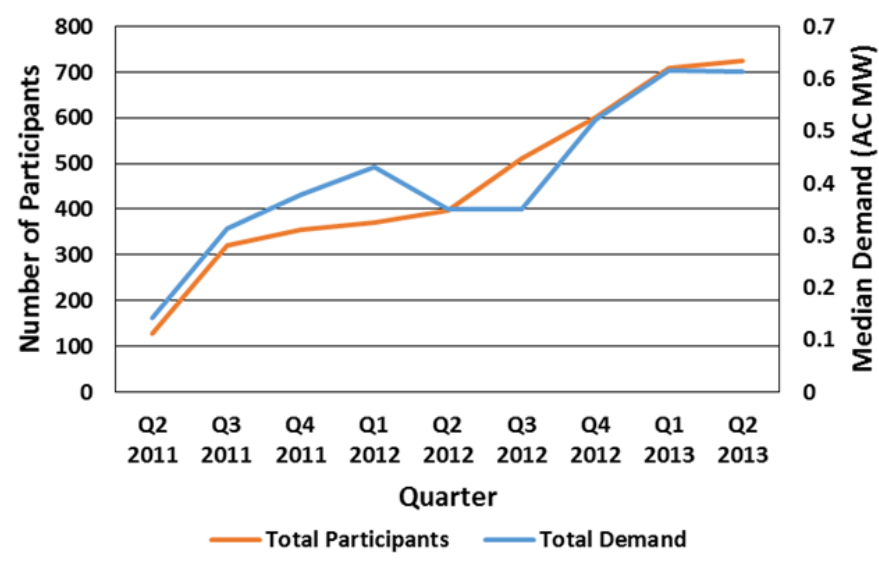

Figure 5. Number of participants and median alternating current (AC) demand in non-TOU territories.

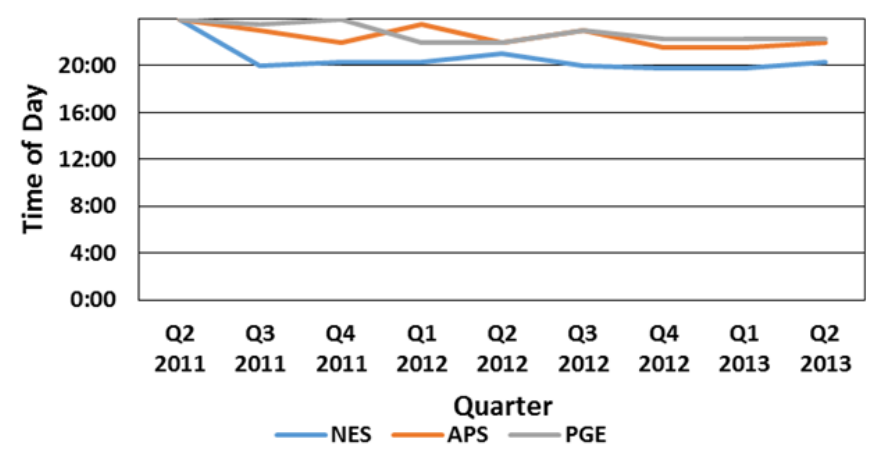

Figure 3. Time of day for peak demand by region.

It is not typically accurate to divide the demand by the number of participants to infer a demand per participant because the participants do charge at different times and contribute to the demand differently. However, because the times of day for the highest demand for these regions are so consistent, there is some correlation. For planning purposes, an electric utility that does not employ TOU rates may estimate that the peak of the median demand in $A C$ kW from PEV charging will occur at approximately 10 p.m. at a rate of 0.8 times the number of PEV drivers in the region.

As seen above, the demand per participant when they charge is determined by the PEV; for The EV Project, this was typically $3.76 \mathrm{~kW}$, with $6.64 \mathrm{~kW}$ for the later-model PEVs.

\section{Time-of-Use Utility Demand Analysis}

Figure 7 shows the relationship between the number of participants and the AC demand in the three utilities' service territories providing TOU rates.

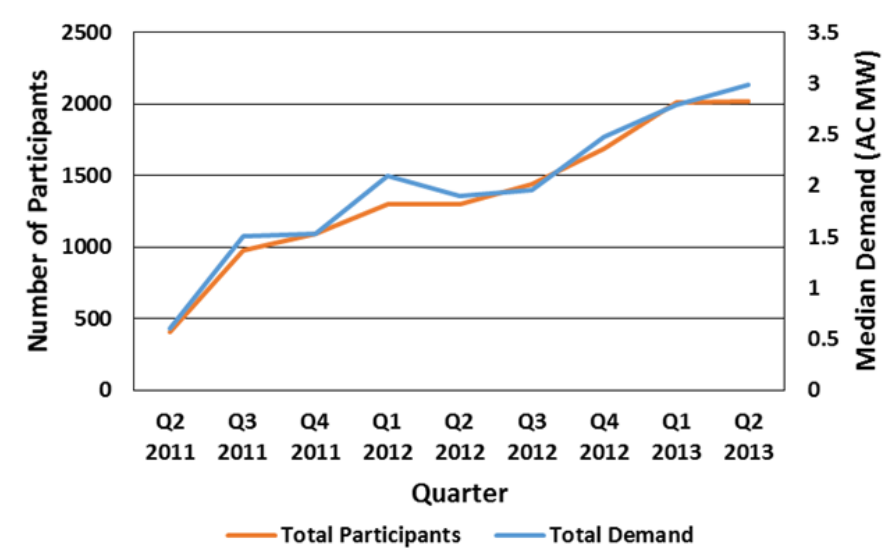

Figure 4. Number of participants and median AC demand in TOU territories.

In these territories, the average number of charges initiated per day per EVSE ranged from 0.61 to 0.95 . Thus, approximately $75 \%$ of the EVSE were used each day to establish the demand noted in Figure 7.

The general shape of the curves noted in Figures 2 and 3 shows that the peak demand for the utility that provides TOU rates is much narrower (i.e., there is less difference between maximum and minimum demands). As a result, the peak of the median demand occurs at a higher multiple of the number of PEV drivers. For these three utilities, the multiple ranged from 1.19 for Georgia Power to 1.98 for PG\&E. For planning purposes, an electric utility that does employ TOU rates may estimate the peak of the median demand in AC kW from PEV charging that will occur at a rate of 1.7 times the number of PEV drivers in the region.

\section{Time-Of-Use Peak}

The Blink EVSE installed by The EV Project for at the residences of participating PEV drivers were easily programmed from the touch screen to start and stop charging at various times during each day of the week. This 
allowed participants in The EV Project to conveniently program their charger to only charge during time periods when energy costs were lowest. As a result, peaks in charging demand occurred in each region of The EV Project where TOU rates were offered. The TOU peak occurred in the three service territories analyzed herein (see Figures 8 through 10).

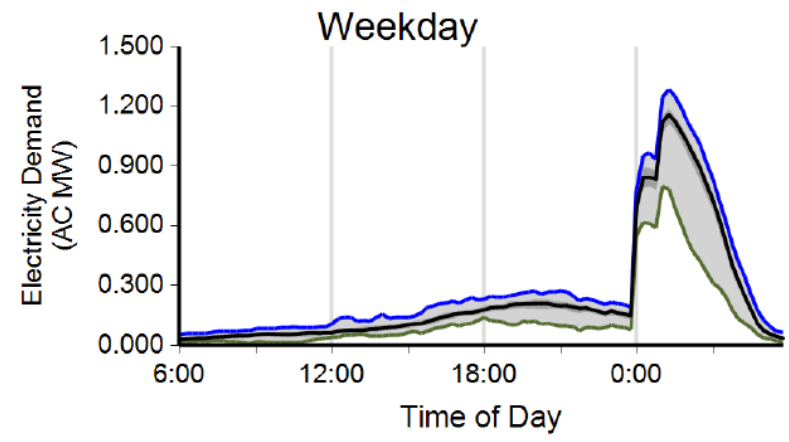

Figure 5. San Diego Gas and Electric residential weekday demand during the second quarter of 2013.

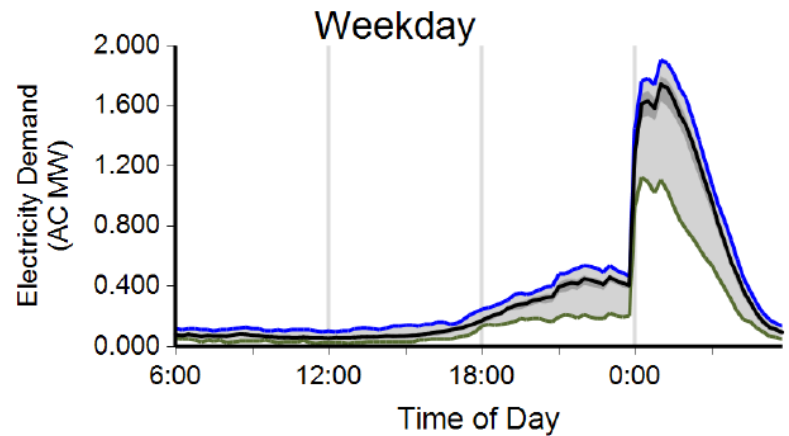

Figure 9. PG\&E residential weekday demand during the second quarter of 2013.

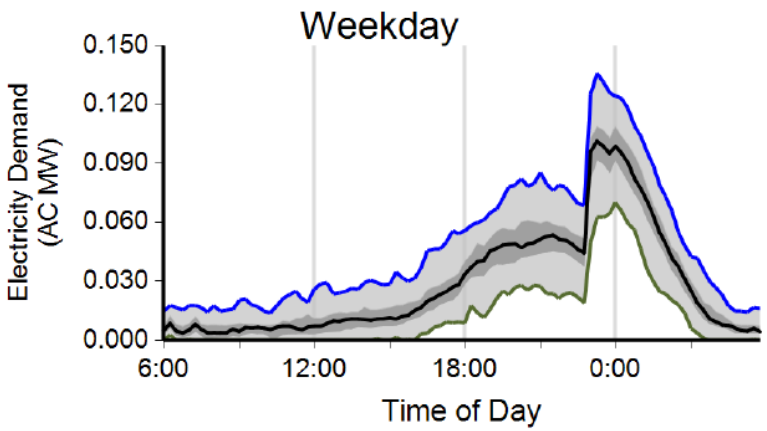

Figure 10. Georgia Power residential weekday demand during the second quarter of 2013.

The Reference 4 report on TOU usage identified that utilities vary in their approach to incentivizing off-peak charging. For these three utilities, San Diego Gas and Electric provides a "super off-peak" that starts at midnight. PG\&E also starts the off-peak time at midnight. Georgia Power has three residential plans affecting TOU: for those charging PEVs, the "super off-peak" starts at 11 p.m. and the general residential off-peak time starts at 7 p.m. For all three utilities, the highest demand essentially occurs within 1 hour of the start of the greatest incentive.

\section{Energy Effects}

\section{Charging Behavior}

PEV drivers do not charge their vehicles every day. The quarterly reports identify the average number of charging events started per EVSE per day. Figure 11 shows this characteristic for the six electric utilities identified above.

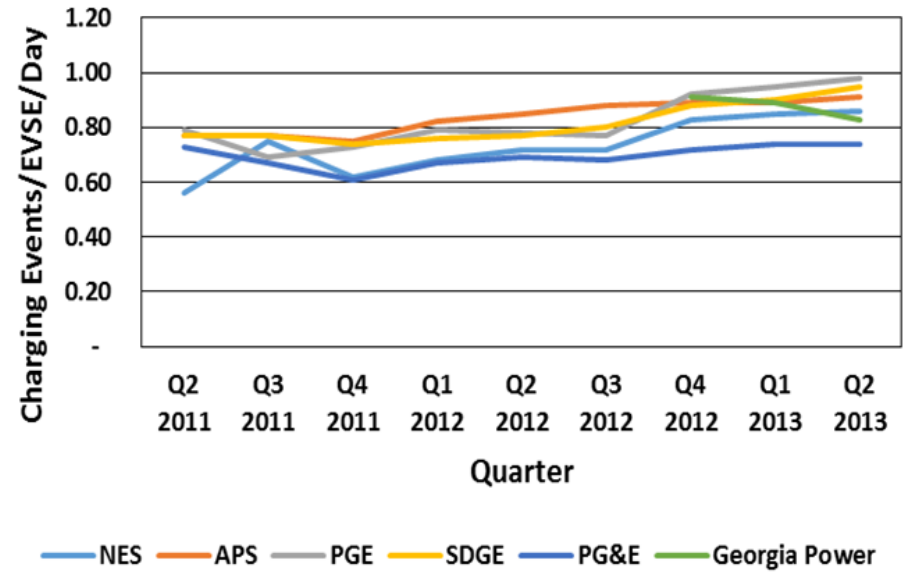

Figure 11. Charging events per EVSE per day.

Atlanta was added as a market later than the other areas and first appeared in The EV Project quarterly reports in the fourth quarter of 2012. PEV behavior in Atlanta followed the other regions in a slight dip over the first couple of months, because the residential EVSE population was small. However, as the population of EVSE grows, the average number of charging events per EVSE per day also grows. Figure 11 shows no obvious difference between the regions where TOU rates are available and where they are not. As expected, the need for charging will depend on PEV usage and not the utility rates. The average number of charging events per EVSE per day for these regions is 0.88 in the second quarter of 2013. In general, the electric utility can expect that $88 \%$ of PEVs will initiate a charge each day.

The average time that a PEV is connected to the residential EVSE during a charge event is shown in Figure 12. The connected time for the third quarter of 2011 in the Nashville Electric Service territory is an obvious data anomaly and was not be used in the analyses herein.

The average EVSE connect time for all territories is 11.7 hours per day. 


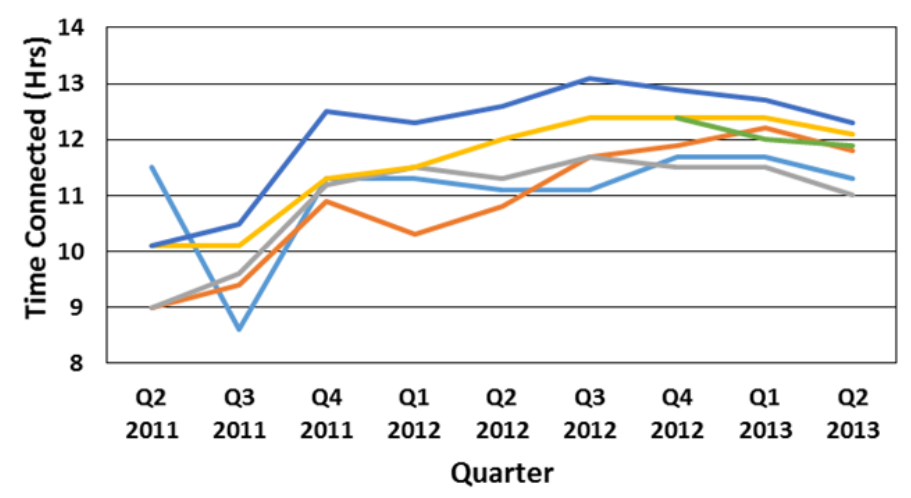

$\longrightarrow$ NES —APS — PGE $\longrightarrow$ SDGE $\longrightarrow$ PG\&E - Georgia Power

Figure 12. Average time connected per EVSE per day.

\section{Energy Consumed}

While the PEV is connected to the residential EVSE for 11.7 hours per charge, it is drawing power for approximately 2.4 hours for each charge. Figure 13 presents this information. For the second quarter of 2013, this value varied from 2.2 to 2.7 hours across the six electric utility territories and is dependent on PEV usage in the territory.

Figure 14 presents the average energy consumed per charging event in these six regions. Again, the energy consumed is dependent on PEV usage in that region. The average of all regions is $8.4 \mathrm{kWh}$.

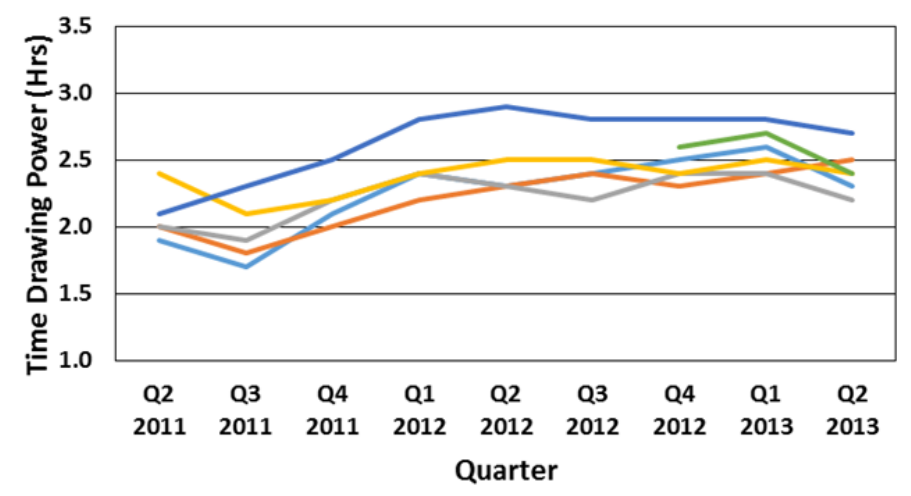

$\longrightarrow$ NES $\longrightarrow$ APS $\longrightarrow$ PGE $\longrightarrow$ SDGE $\longrightarrow$ PG\&E — Georgia Power

Figure 13. Average time PEV drawing power per charge.

In many of these graphs, an apparent trend is occurring from about the fourth quarter of 2012 to the second quarter of 2013 in that the average energy per charging event is decreasing, along with the average time the PEV is drawing power. The average time the PEV is connected is also decreasing; however, it has no real effect on the energy transferred. At the same time, Figure 11 shows an increasing number of EVSE connected per day. This would have an off-setting effect. While the energy per charge is decreasing, the number of charges is increasing. It appears that PEV drivers are still working on developing charging habits in all of the regions.

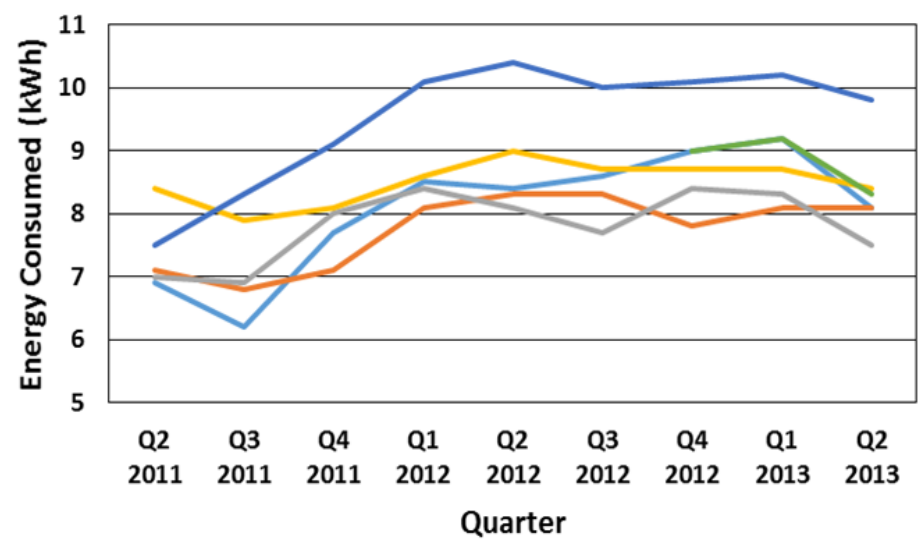

$\longrightarrow$ NES —APS P $-\mathrm{PGE} \longrightarrow$ SDGE $\longrightarrow$ PG\&E — Georgia Power

Figure 14. Average energy consumed per charging event.

\section{Residential Electric Vehicle Supply Equipment Charge Profile}

The average charge event noted here consumes $8.4 \mathrm{kWh}$ of energy. An actual charge event delivering this energy was identified from The EV Project charge data. Using the 15-minute average energy values, the profile shown in Figure 15 was developed.

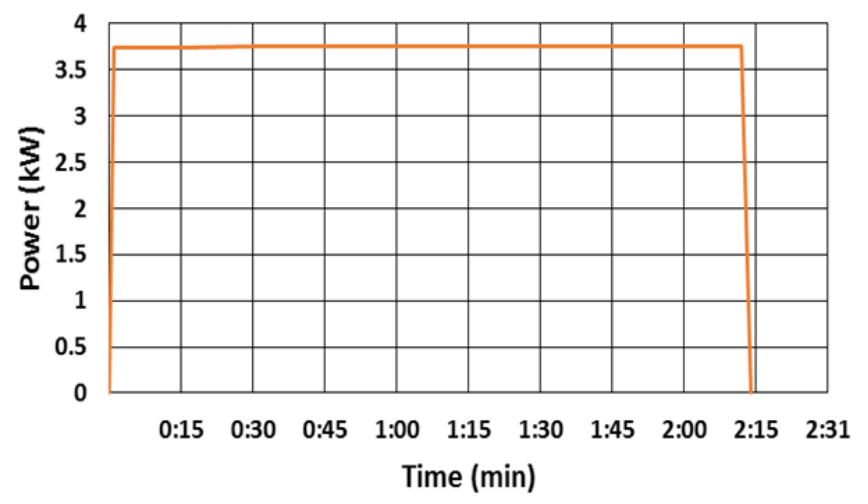

Figure 15. Charge profile for residential AC Level 2 EVSE.

Peak power during each 15-minute period varies between 3.74 and $3.76 \mathrm{~kW}$, depending on the PEV's charge acceptance. Charge acceptance is determined by the PEV's onboard battery management system. Many factors affect the PEV's charge acceptance, including battery, ambient temperature, and the state of charge. It appears that in this example, the PEV was able to accept the charge at its highest design charge rate. 


\section{Conclusions}

At this writing, the adoption of PEVs is still quite low. Although there have been many thousands of PEVs sold in the months since The EV Project concluded, they still represent less than 1\% of all vehicles sold. Many electric utilities are involved in planning for the addition of significant numbers of PEVs to their service territories. In response to the question of "What is the impact on the electric grid?" some guidance can be provided from The EV Project.

For electric utilities with concern for residential peak demand, the implementation of TOU rates can be effective in shifting loads to off-peak times. Once initiated, the utility can expect a charging demand to peak within about 1 hour of the start of the time with greatest incentive. They can also expect the demand period to be of shorter duration than would be expected without TOU rates. For planning purposes, the utility may expect the peak median demand to be at approximately $1.7 \mathrm{~kW}$ times the number of PEV drivers in the region.

Electric utilities that do not provide TOU rates may expect the peak of the median demand to occur at about 10 p.m. at approximately $0.84 \mathrm{~kW}$ times the number of PEV drivers in the region. Without TOU rates, the peak is flatter and is later than the typical weekday electric system peak demand.

PEV drivers do not charge their vehicle every day. However, each day, approximately $88 \%$ of PEV owners in a region will initiate a charge of their PEV. This average charge will consume $8.4 \mathrm{kWh}$ of energy over a 2.4-hour period. The charge profile of a PEV that fully accepts the charge at the maximum rate is quite flat (see Figure 15).

As PEV manufacturers increase the power at which their vehicles can charge, PEV charging will result in greater demand peaks. However, the charge duration will be shorter for the same total energy returned to the battery.

\section{About The EV Project}

The EV Project was the largest PEV infrastructure demonstration project in the world, equally funded by the United States Department of Energy (DOE) through the American Recovery and Reinvestment Act and private sector partners. The EV Project deployed over 12,000 AC Level 2 charging stations for residential and commercial use and over 100 dual-port direct current fast chargers in 17 U.S. regions. Approximately 8,300 Nissan LEAFs ${ }^{\mathrm{TM}}$, Chevrolet Volts, and Smart ForTwo Electric Drive vehicles were enrolled in the project.

Project participants gave written consent for EV Project researchers to collect and analyze data from their vehicles and/or charging units. Data collected from the vehicles and charging infrastructure represented almost 125 million miles of driving and 4 million charging events. The data collection phase of The EV Project ran from January 1 , 2011, through December 31, 2013. Idaho National Laboratory is responsible for analyzing the data and publishing summary reports, technical papers, and lessons learned on vehicle and charging unit use.

\section{Company Profile}

Idaho National Laboratory is one of DOE's 10 multi-program national laboratories. The laboratory performs work in each of DOE's strategic goal areas: energy, national security, science, and the environment. Idaho National Laboratory is the nation's leading center for nuclear energy research and development. Day-to-day management and operation of the laboratory is the responsibility of Battelle Energy Alliance.

For more information, visit avt.inl.gov/evproject.shtml and avt.inl.gov/chargepoint.shtml.

\section{References}

${ }^{1}$ http://avt.inl.gov/pdf/EVProj/126876-663065.clustering.pdf.

${ }^{2}$ http://www.sdge.com/customer-choice/customerchoice/dynamic-load-profiles.

${ }^{3}$ http://www.teslamotors.com/charging/\#/basics.

${ }^{4}$ http://avt.inl.gov/pdf/EVProj/125348-714937.pev-driver.pdf. 